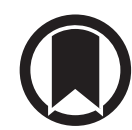

CrossMark

\title{
Malignant pleural mesothelioma: history, controversy and future of a manmade epidemic
}

\author{
Oluf Dimitri Røe $\mathrm{e}^{1,2,3}$ and Giulia Maria Stella ${ }^{4}$
}

\begin{abstract}
Affiliations: ${ }^{1}$ Dept of Cancer Research and Molecular Medicine, Norwegian University of Science and Technology (NTNU), Trondheim, Norway. ${ }^{2}$ Cancer Clinic, Levanger Hospital, Nord-Trøndelag Health Trust, Levanger, Norway. ${ }^{3}$ Dept of Oncology, Clinical Cancer Research Center, Aalborg University Hospital, Aalborg, Denmark. ${ }^{4}$ Laboratory of Biochemistry and Genetics, Pneumology Unit, Dept of Molecular Medicine, University and Fondazione IRCCS, Policlinico San Matteo, Pavia, Italy.
\end{abstract}

Correspondence: Oluf Dimitri Røe, Dept of Cancer Research and Molecular Medicine, NTNU, Erling Skjalgssons gt. 1, 7491 Trondheim, Norway. E-mail: oluf.roeantnu.no

ABSTRACT Asbestos is the term for a family of naturally occurring minerals that have been used on a small scale since ancient times. Industrialisation demanded increased mining and refining in the 20th century, and in 1960, Wagner, Sleggs and Marchand from South Africa linked asbestos to mesothelioma, paving the way to the current knowledge of the aetiology, epidemiology and biology of malignant pleural mesothelioma. Pleural mesothelioma is one of the most lethal cancers, with increasing incidence worldwide. This review will give some snapshots of the history of pleural mesothelioma discovery, and the body of epidemiological and biological research, including some of the controversies and unresolved questions. Translational research is currently unravelling novel circulating biomarkers for earlier diagnosis and novel treatment targets. Current breakthrough discoveries of clinically promising noninvasive biomarkers, such as the 13-protein signature, microRNAs and the BAP1 mesothelioma/cancer syndrome, are highlighted. The asbestos history is a lesson to not be repeated, but here we also review recent in vivo and in vitro studies showing that manmade carbon nanofibres could pose a similar danger to human health. This should be taken seriously by regulatory bodies to ensure thorough testing of novel materials before release in the society.

@ERSpublications

Malignant pleural mesothelioma is a cancer with increasing death tolls due to the past and present use of asbestos http://ow.ly/DhA2y

\section{Background}

History of asbestos use and mesothelioma discovery

Asbestos (from the Greek word meaning "inextinguishable") is the term for a family of naturally occurring minerals that readily separate into thin fibres and are found in many parts of the world. The term amiantus (from the Greek "untaintable", currently used in modern Greek for asbestos) was used by Pliny the Elder (23-79 AD), who described that this material was mined in the mountains of Arcadia, could be spun and woven into material, and was resistant to fire [1]. The Greek geographer Strabo (63/64 BC-ca. $24 \mathrm{AD}$ ) described similar use of the so-called "Karystian stone" from the ancient quarry on the island of Evvia in Greece, and Dioscorides (ca. 40-90 AD) described in his De Materia Medica the use of this stone for weaving napkins that could be cleaned and whitened by fire [1]. In Finland, asbestos was used in pottery 4500 years ago, and in Norway, bucket-shaped pottery tempered with crushed asbestos was used

Received: Aug 212014 | Accepted after revision: Sept 222014

Conflict of interest: None declared.

Provenance: Submitted article, peer reviewed.

Copyright OERS 2015. ERR articles are open access and distributed under the terms of the Creative Commons Attribution Non-Commercial Licence 4.0. 


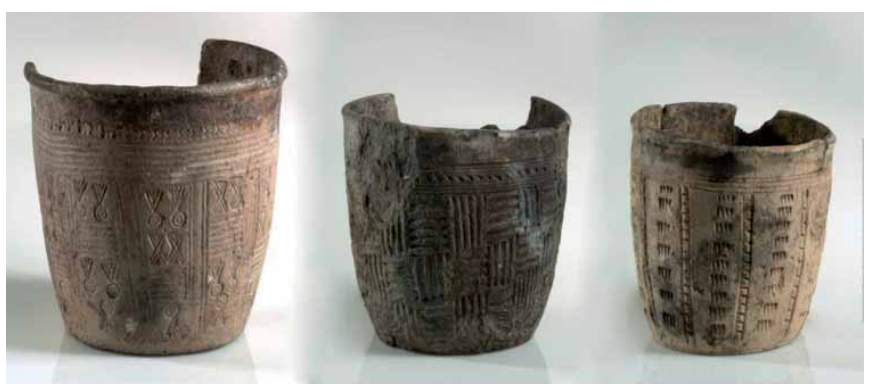

FIGURE 1 Bucket shape pottery from Telemark, also found in several other areas in Norway, from the Bronze Age to the Roman period (400-575 AD). They were used for cooking and storage of food, with estimated asbestos content of 65-80\%. Image courtesy of Asbjørn Engevik, University Museum of Bergen, University of Bergen, Bergen, Norway. (c) Svein Skaare, University Museum of Bergen.

for storing and making food in the Late Roman and Migration periods (ca. 350-475 AD) (fig. 1) [2]. Marco Polo (1254-1324 AD) also described asbestos mining in China, so there is clear evidence of asbestos use among various cultures since ancient times [3]. However, mass mining and use did not start until the 20th century, due to the applications of asbestos as insulation against heat, fire and corrosion, and its tensile strength. Asbestos was widely used for insulation of water and combustion pipes, materials used for house construction and shipbuilding, car brakes and gaskets, even toys, jewellery, and cigarette filters; at its peak, 3000 products were registered [4].

The first report of a pleural tumour was in 1767 by Joseph Lieutand; however, mesothelioma was first characterised as an entity by Klemperer and Rabin in 1931 [5]. It took almost a further 30 years to become widely accepted as a separate cancer entity. The definitive epidemiological study linking mesothelioma to asbestos came from South Africa, published in 1960 by J.C. Wagner, C.A. Sleggs and P. Marchand, showing that mesothelioma was very prevalent in people living or working in the crocidolite asbestos mine area [6]. Later, several studies from the USA, Europe, Australia and Japan verified asbestos inhalation as the aetiological cause of mesothelioma [5,7-11]. The role of asbestos as a separate carcinogen in lung cancer was also described and, even more dramatically, combining cigarette smoking with asbestos increased the risk of lung cancer from 10- to almost 100-fold over that of the unexposed [12]. Asbestos inhalation can also induce: malignant peritoneal mesothelioma, which accounts for approximately $30 \%$ of all mesotheliomas; pleural plaques, which are benign and not predictive of mesothelioma; and asbestosis, a pneumoconiosis that may be fatal and was recently shown to increase the risk of cancer of the pharynx, stomach, colon and ovaries, as reviewed in the 2012 IARC Monograph [10]. However, this review will focus on malignant pleural mesothelioma, hereafter referred to as "mesothelioma". Pleural mesothelioma is a relatively chemotherapy- and radiation-resistant cancer that is usually diagnosed in a late stage and has a median survival of 12 months with the current state-of-the art treatment with pemetrexed and platinum.

\section{Asbestos and nonasbestos fibre types, exposure and mesothelioma epidemiology}

Asbestos is classified into two main families, the serpentines and the amphiboles. The serpentines consist of one type, chrysotile, with characteristic short, curly fibres, also called "white asbestos" due to its colour, which accounts for 95\% of asbestos in commercial use. The amphiboles, with straight, longer fibres, include crocidolite or "blue asbestos", amosite, tremolite, actinolite and anthophyllite, and a thorough review of their physical and biological properties has recently been published [10].

The risk of mesothelioma has previously been correlated with fibre type, where shorter fibres (chrysotile) were assumed to be less carcinogenic. This was mainly due to some research findings of high levels of long (amphibole) fibres in the lungs of the deceased patients and the animal experiments by STANTON and WRENCH [13] leading to the "Stanton fibre hypothesis". Moreover, some researchers claimed that chrysotile could generate mesothelioma only if it was contaminated with an amphibole, the "tremolite contamination hypothesis" [14]. Nevertheless several animal models, including the early work of WAGNER et al. [15] from 1974, have pointed to the conclusion that chrysotile is an important carcinogen and risk factor, not only for mesothelioma, but also for lung cancer; the current international perception, according to the World Health Organization (WHO) and the International Agency for Research on Cancer (IARC), is that all types of asbestos are classified as class I carcinogens [10], and that exposure to asbestos is the major cause of both pleural and peritoneal mesothelioma [16]. These findings resulted in the banning of asbestos production and import in several European countries at various time-points after 1970, and in the European Union as late as $2005[10,17]$. 
There is a known dose-response pattern of asbestos exposure with mesothelioma and lung cancer but, as stated by the IARC and WHO, no safe lower threshold has been identified. Moreover, BERNSTEIN et al. [18] discovered that not only were people working with asbestos at risk but also their families, due to cleaning of contaminated work clothes, and people living close to places were asbestos was mined or processed. In Italy, in Casale Monferrato (Eternit factory), Broni and Bari (Fibronit factory), an epidemic of mesothelioma was registered among inhabitants who were never exposed to the local asbestos factories, where $25 \%$ and $33 \%$ of cases, respectively, had only one risk factor: living close to an asbestos cement factory. The calculated risk was very high (OR 10.5 and 5.25, respectively) for those living $<500 \mathrm{~m}$ from the factory and the fibre burden in the lungs of deceased cases was 10-fold that in those from other areas [19].

In most epidemiological surveys, mesothelioma is more common in men (typical male/female ratios were 5/1) and some have inferred that susceptibility is correlated with sex. However, other studies have shown this to be related to exposure and, typically, there is low asbestos exposure in women because the occupations that confer exposure are traditionally men's work. In occupations were women were most exposed, the majority of the victims were women [15].

The extent of import and use of asbestos in a country is closely correlated to mesothelioma incidence. Norway, a small country but with a solid cancer registry and asbestos statistics, exemplifies this point, where the peak of asbestos import was in 1970-1975 and the apparent mesothelioma peak is today, 40 years later (fig. 2). International epidemiological surveys have estimated that the incidence peak in Europe will be reached around 2020 [20].

Asbestos may also cause lung cancer; up to 20000 asbestos-related lung cancers and 10000 mesotheliomas are estimated to occur annually across the population of western Europe, Scandinavia, North America, Japan and Australia [21], while registrations are not available in areas that still use asbestos (eastern Europe, South America, Africa, and the rest of Asia, including China). WHO reports that 125 million people encounter asbestos in the workplace. In 2004, asbestos-related lung cancer, mesothelioma and asbestosis from occupational exposures resulted in 107000 deaths and 1523000 disability-adjusted life-years, and we know that these figures are increasing. In addition, several thousands of deaths can be attributed to other asbestos-related diseases, as well as to nonoccupational exposures to asbestos [22]. Currently, the incidence of the disease is still increasing in most countries of the world, and only in countries in which asbestos control measures were taken during the 1970s, such as Sweden and the UK, has this increase levelled off [23]. Thus, the worldwide epidemic is in its beginning [24, 25], and in countries that produce and/or use asbestos, such as China, India, Russia, Zambia, Colombia and Kazakhstan, a sharp rise in incidence could be expected [26-29].

Environmental exposure to carcinogenic fibres that exist on the earth surface is another, more uncontrollable risk factor. An old tradition of whitewashing the houses with soft tremolite in Metsovo,

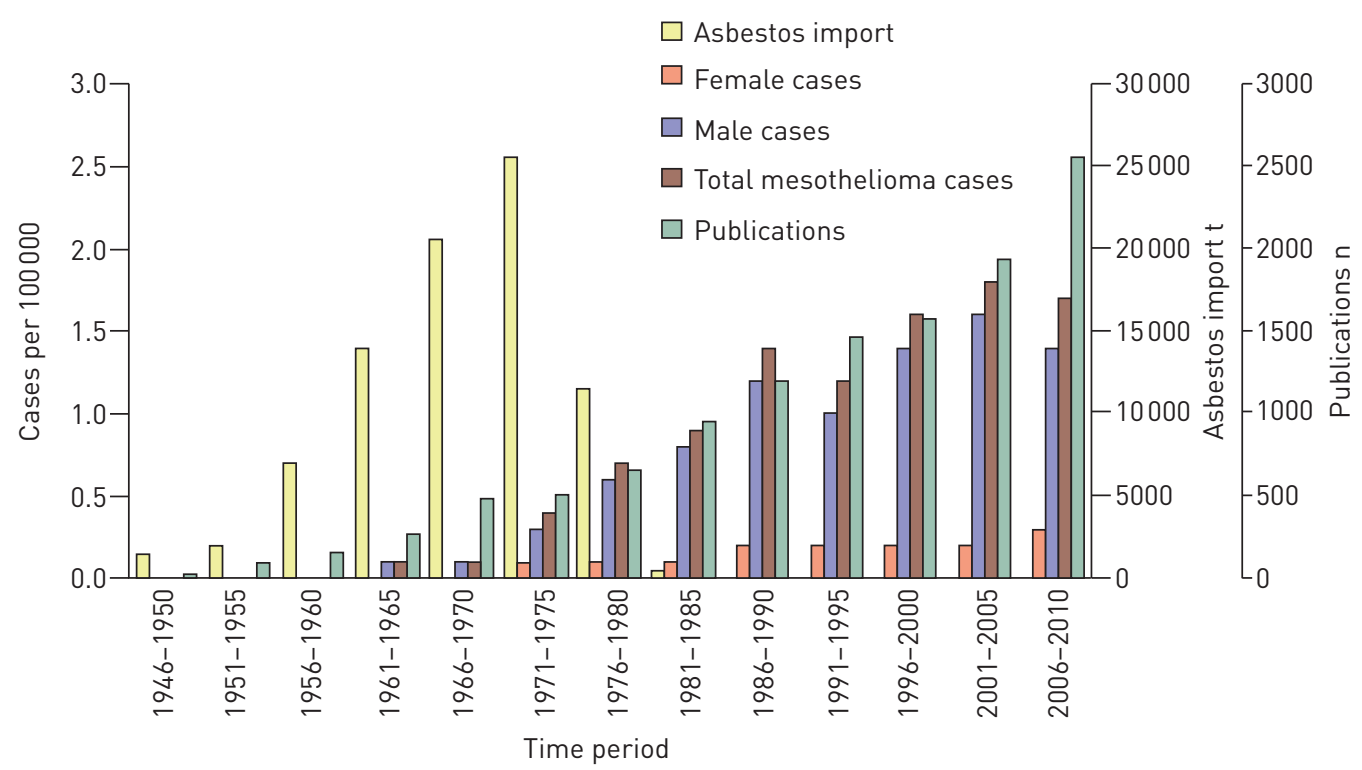

FIGURE 2 Cumulative amounts in 5-year periods from 1946 to 2010 of import of raw asbestos to Norway (data from Statistics Norway (www.ssb.no), 2002), incidence rates of malignant mesothelioma per 100000 among males and females in Norway (International Classification of Diseases (10th Edition) diagnosis code C45; data from the Norwegian Cancer Registry (www.kreftregisteret.no)) and cumulative number of publications in PubMed with the key word "mesothelioma". 
Greece, was the reason for a cluster of mesotheliomas in young women, as women used to do this work [30]. Another important study by Luo et al. [26] documented that the farmers exposed to crocidolite-containing soil in Da-Yao, a province of China, had a death rate of mesothelioma of 365 per million, in contrast to, for example, Norway, with 14 cases per million. Erionite, an asbestos-like mineral from the soil, was revealed as the main factor of mesothelioma in young people in some villages in Cappadocia in Turkey, were more than $50 \%$ of inhabitants died from mesothelioma [31]. The study of family trees in these villages showed a strong linkage to certain families, indicating a genetic susceptibility for developing this disease, probably in an autosomal dominant way [32]. Recently, a breakthrough in the study of mesothelioma susceptibility showed that mutations in the gene BAP1 (BRCA1-associated protein 1) were strongly associated with mesothelioma [33]. This will be discussed later in this review.

\section{lonising radiation and mesothelioma}

Long-term effects of ionising radiation have been aetiologically linked to mesothelioma, although in a much smaller group of individuals than the asbestos exposed. The risk of developing mesothelioma was significantly higher in cases previously exposed to $\alpha$-particle-emitting agents, such as the radioactive contrast Thorotrast. It is also well-documented that mesothelioma is over-represented in testicular cancer and Hodgkin's lymphoma survivors who have been treated with external radiotherapy [17, 34-36]. However, today, due to knowledge of secondary cancer formation and improved alternatives for these cancers, these treatments are rarely used.

\section{Polio vaccine, simian virus 40 and mesothelioma}

One very fascinating, but also very disturbing, hypothesis put forward in 1994 is that inadvertent inoculation of millions of people with an oncogenic virus at the end of the 1950s could be a cause of mesothelioma and other types of cancer [37]. This theory has still not been completely discarded due to the facts reviewed below.

The first inactivated poliovirus vaccine (IPV) and live oral poliovirus vaccine were prepared in primary cell cultures derived from rhesus monkey kidneys. Studies of these vaccines led to the discovery of a new DNA virus called simian virus (SV)40 in 1959 [38], a virus endemic in rhesus monkeys. SV40 did not induce any serious clinical disease in the animals but caused vacuolisation of green monkey cell cultures, and was found to be highly oncogenic in rodents, inducing mesothelioma, ependymoma, osteosarcoma and non-Hodgkin's lymphoma, apparently partly dependent on the route of injection [39]. The formaldehyde treatment that was used to prepare IPV failed to completely inactivate SV40, causing some batches of IPV to contain infectious SV40. As a result, it has been estimated that 30-100 million people in the USA and many more worldwide received potentially contaminated vaccines prepared during the years 1955-1963 [40].

The first known biological effect of SV40 was the development of numerous tumours (polyoma) in hamsters, but also the ability to transform human cell lines. This archetypal virus effect on eukaryotic cells has been crucial in revealing important, basic functions such as replication, transcription and transformation [38]. The strong and consistent relationship between experimental SV40 infection and cancer development in rodents motivated the investigation of its carcinogenic potential in humans. SV40 DNA sequences have repeatedly been reported in cases of human cancers of essentially the same types observed in rodents [37, 41, 42]. In a meta-analysis that included 528 mesothelioma cases and 468 controls from 15 studies, the combined odds ratio for the presence of SV40 DNA sequences in mesothelioma tumour tissue was very high (OR 17, 95\% CI 10-28) [43]. Other studies of SV40 sequences in tumour tissue have, however, seriously questioned these results, suggesting that positive findings were caused by contamination or other laboratory artefacts $[44,45]$. Even if it is a fact that human infection of SV40 took place on a large scale in the early days of polio vaccination, epidemiological studies have not shown any clear correlation to cancer [46].

The interpretation of the repeated finding of SV40 in human tumours is still controversial. However, recent studies showed that animals infected with SV40 or transfected with SV40 large T-antigen (TAg) were extremely susceptible to asbestos carcinogenesis, and this is currently used as an in vivo model of SV40 as a co-carcinogen for mesothelioma development $[47,48]$. A molecular epidemiological study has also indicated a co-carcinogen role of SV40 and studies addressing this question are awaited [49].

\section{Pathophysiology}

Normal pleura physiology and fibre clearance

The pleura is a thin and elastic membrane that covers the entire inner surface of the thoracic cavity. It is almost continuous, so it constitutes an expandable sac with a small amount of lubricating fluid for smooth movement of the thoracic cage, lungs, heart and inner organs. Parietal pleura cover the thoracic wall, mediastinum, heart and diaphragm, and the visceral pleura cover the lungs (fig. 3). 


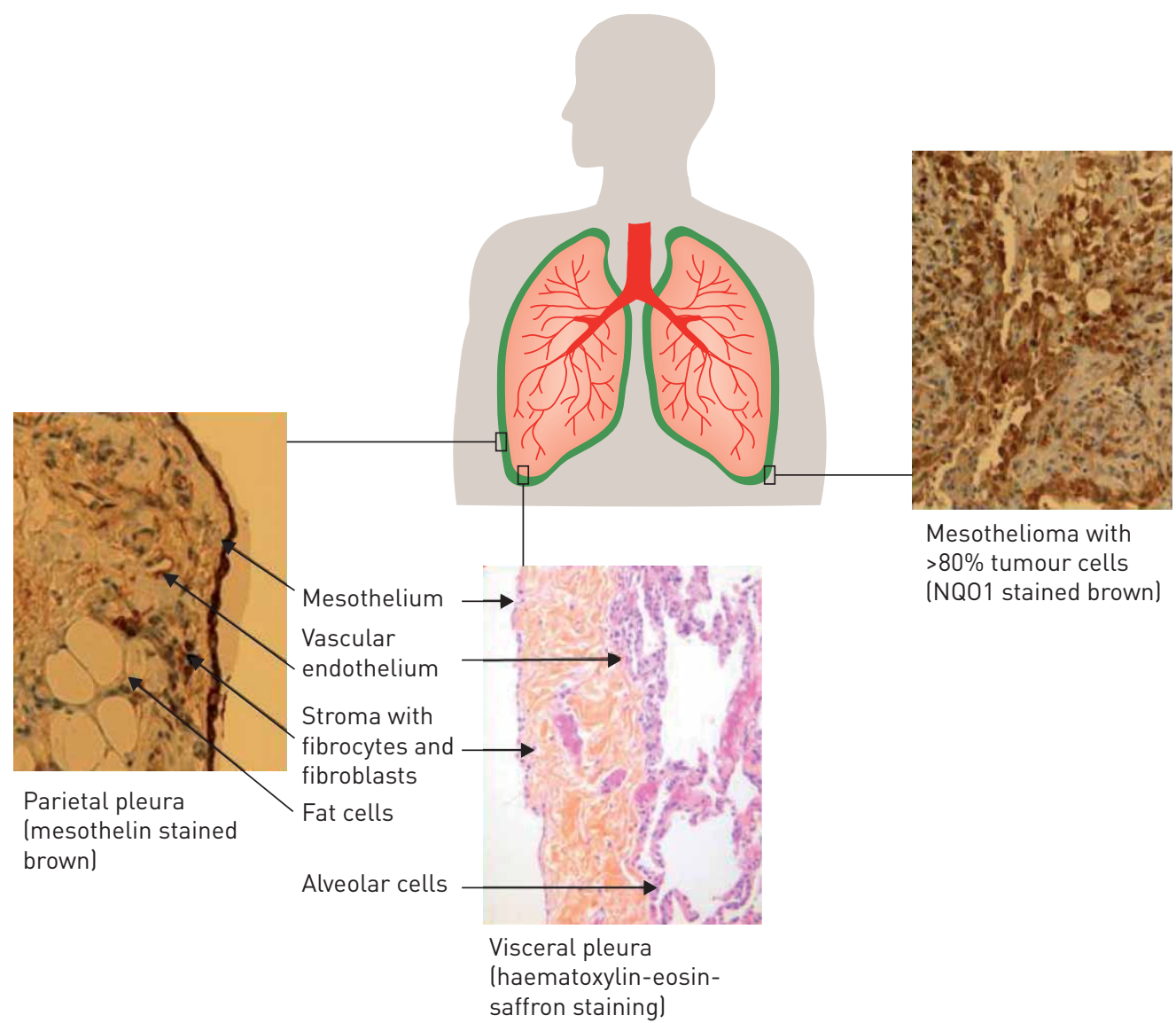

FIGURE 3 Representation of the normal parietal pleura, the visceral pleura and pleural mesothelioma with the most abundant cell types. Reproduced from [50] with permission from the publisher.

Pleura is of mesodermal origin, is present at the seventh week of gestation and comprises five layers: 1) a single layer of mesothelial cells; 2) a thin mesothelial connective tissue layer with a basal lamina; 3 ) a thin superficial elastic layer; 4) a loose connective tissue layer containing adipose tissue, fibrocytes, fibroblasts, mast cells and other mononuclear cells including telocytes [51], blood vessels, nerves and lymphatics; and 5) a deep fibroelastic layer that adheres tightly to the underlying structures (lung, thoracic muscle, etc.). Studies of mesothelial cells have shown them to have a variety of functions, including inflammatory responses and phagocytosis of fibres [52].

Parietal and visceral pleura are similar, but have also significant differences in structure and function (table 1). Interestingly, genome-wide analysis of parietal versus visceral pleura from the same noncancer patients reflected this, as described previously in our study (fig. 4) [50].

Why is the pleura, and especially the parietal pleura, the target of asbestos disease? Inhaled fibres enter the visceral pleura and the pleural space to the parietal pleura through the alveoli, or retrograde through the lymphatic vessels [54]. This may be the reason why fibres of different sizes are more abundant in various segments, where the vast majority of chrysotile, the shorter asbestos fibre, is found in parietal pleura [55, 56], while crocidolite and other amphibole fibres are mostly found in the lung parenchyma $[56,57]$. Moreover, the chronic inflammatory reaction believed to precede mesothelioma is mostly around the stomata and the lymphoid patches called Kampmeier's foci located in the basal part of the parietal pleura, which is the most common site of mesothelioma.

\section{Origin and site of the mesothelioma cell}

Mesothelioma is derived from cells of the pleura, peritoneum or tunica vaginalis, of which pleural location accounts for about $70 \%$ of cases [58]. Epithelial mesothelioma, with its cuboidal cells, is the most common subtype, while the sarcomatous type, with spindle-like cells, and the mixed subtype are rarer.

Until recently, it has been taken for granted that the mesothelial cell is the mesothelioma progenitor cell. However, when normal mesothelial cells are damaged, both regeneration from normal mesothelium and 
TABLE 1 Structural and functional differences of the parietal and visceral pleura

\begin{tabular}{lcc} 
Biological parameters & Parietal pleura & Visceral pleura \\
\hline Mesothelial microvilli & Fewer (fewest on the costal surface) & More abundant \\
Mesothelial cell form & Flat & Cuboidal \\
Elasticity & Low & High \\
Permeability & High & Low \\
Tight junctions & Fewer & More \\
Intramembranous organisation & Loose & Complex and tight \\
Innervation & Somatic, intercostal nerves & Vagus, sympathetic trunk \\
Pain receptors & Yes & No \\
Vascularisation & Abundant & Poor \\
Drainage of pleural fluid and particles & Most & Little \\
Pleural fluid origin & Most & Little \\
Stomata & Yes, basal part & No \\
Lymphatic drainage & Yes & No \\
Kampmeier's foci & Abundant (mostly intercostal spaces) & Less, closer to alveoli than the mesothelium
\end{tabular}

Information from [53].

development from submesothelial multipotential stem cells are possible mechanisms of repair [59, 60]. Moreover, recent studies showed that adipocytes, circulating multipotential fibrocytes and adult bone marrow-derived stem cells are able to differentiate into both epithelial and mesenchymal cells [61-63]. Interestingly, mesothelial cells also have the ability to change phenotype to become smooth muscle cells and fibroblasts in internal organs and their vasculature, so normal mesothelial cells are multipotential, similar to stem cells [64]. The question that arises is whether the mesothelioma progenitor cell is derived from a submesothelial multipotential cell, from the highly differentiated mesothelial cell or both?

An obvious problem that remains unresolved is why pleural plaques and, most probably, mesothelioma primarily evolve in the parietal pleura [65]. This issue has not been studied in depth, but the aforementioned factors have been hypothesised. However, there is no general consensus on this point. The evidence supporting a parietal origin is that cases with only parietal affection (stage T1a) have a survival of 32.7 months versus only 7 months in $\mathrm{T} 1 \mathrm{~b}$, which involves parietal and visceral pleura, indicating that the parietal lesion is an earlier event [65]. Moreover, to our knowledge, cases where only visceral pleura is affected have not been reported [66]. The current concept is that the tumour grows in a locoregional pattern, spreading from the parietal to the visceral pleura and invading the surrounding structures, which induces the clinical picture of pleural fluid, pain and dyspnoea.

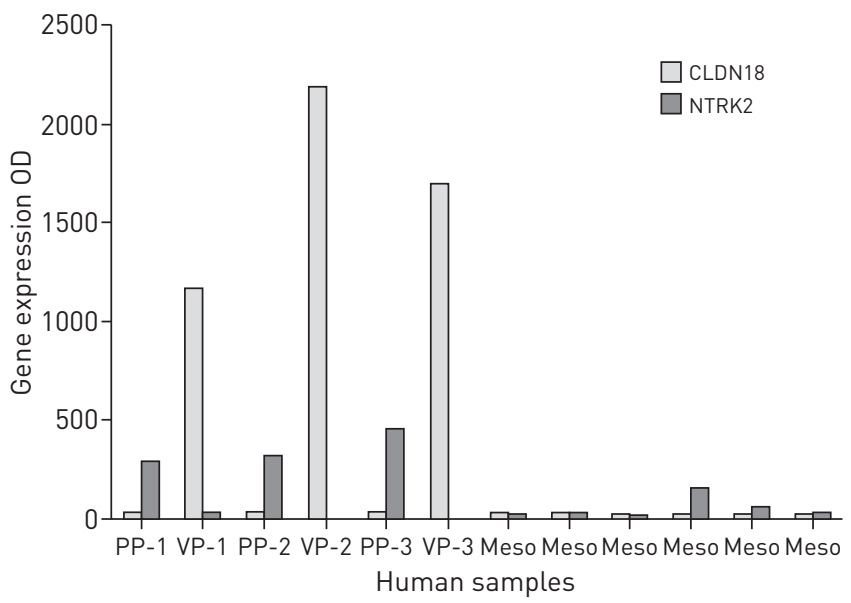

FIGURE 4 Differential gene expression in human samples of the parietal pleura (PP), the visceral pleura (VP) and mesothelioma (meso). PP and PV from the same noncancer patients were analysed with a genome-wide mRNA array (unpublished observations). Tight junctions are much more abundant in the visceral pleura, and several claudins, including the claudin 18 gene (CLDN18), were highly expressed in VP. The type 2 neurotrophic tyrosine kinase receptor gene (NTRK2), which is abundantly expressed in nerve cells, is highly expressed in the PP. Both CLDN18 and NTRK2 had low expression in most of the mesotheliomas analysed. OD: optical density. 
Mesothelioma carcinogenesis and molecular profiling

Knowledge of the cytogenetic and molecular aspects of mesothelioma has progressed substantially in recent years, and high-throughput analyses have revolutionised molecular characterisation and our understanding of its underlying biological complexity. However, the carcinogenic mechanism of asbestos is not fully understood. Here, a short overview is provided.

The currently accepted concept is that inhaled asbestos or other carcinogenic fibres end up in the pleura, inducing cytotoxicity, DNA damage, frustrated phagocytosis and chronic inflammation [67, 68]. During the latency period of 20-60 years, several key mechanisms of the mesothelium, such as chromosomal aberrations and epigenetic changes (e.g. promoter hypermethylation at tumour suppressor loci), result in functional disturbances measured by gene, microRNA and protein expressions [69-73]. Asbestos fibres are clastogenic and cytotoxic in vitro, and induce abnormal segregation at mitosis. Their in vitro and in vivo transforming activity has been related to fibre dimensions, durability and surface properties [12]. Based on epidemiological data, the long, thin amphiboles (crocidolite and amosite) have been regarded as the most carcinogenic, while the short and curly serpentines (chrysotile) are regarded as less dangerous, but undoubtedly carcinogenic. As noted previously, more recent data point out that chrysotile should probably not be considered less dangerous [74-76].

Cytogenetic studies have shown that mesotheliomas have highly complex and variable chromosomal aberrations [77], and only few features are shared between patients. Loss-of-heterozygosity analyses have demonstrated frequent deletions of specific sites within chromosome arms $1 p, 3 p, 6 q, 9 p, 13 q, 15 q$ and 22q. Two of these regions are most frequently altered, the tumour suppressors $C D K N 2 A-A R F$ at $9 \mathrm{p} 21$, and NF2 at 22q12. Homozygous deletion appears to be the major mechanism affecting CDKN2A-ARF, whereas inactivating mutations coupled with allelic loss occur at the NF2 locus [78]. Mesothelioma, as opposed to most other cancers, rarely has mutated TP53, but loss of p14 ${ }^{\mathrm{ARF}}$ indirectly inactivates p53 [79]. Restoring $\mathrm{p} 14^{\mathrm{ARF}}$ in a mouse model suppressed tumour growth significantly, showing the importance of this mechanism [80]. Furthermore, retinoblastoma protein and p53 can be inactivated by SV40 TAg, which has been a suggested mechanism of mesothelioma progression [81]. NF- $\kappa \mathrm{B}$ (nuclear factor, $\kappa$-light chain enhancer of activated B-cells) has been shown to be a survival factor in transformed human mesothelial cells and human mesothelioma cells. It acts as a survival factor in human mesothelial cells exposed to asbestos fibres [82]. Proteasome genes are overexpressed in human mesothelioma. Proteasome inhibition was shown to suppress NF- $\mathrm{BB}$ activity in malignant mesothelioma cells, and induce cell cycle blockade and apoptosis in vitro, as well as tumour growth inhibition in vivo [83]. Recently, KRAS and TP53 missense mutations were shown to induce not only lung carcinomas but also aggressive mesotheliomas in mice [84], showing that only two gene alterations also can induce this tumour. Cell surface heparan sulfate proteoglycans, particularly syndecans, have recently been shown to be expressed in mesotheliomas, interact with growth factors and matrix components, and play a role in epithelialmesenchymal transition of epithelial mesothelioma to the sarcomatous type [85].

Extracellular signal-regulated kinases (ERKs) are a family of molecules with distinct roles in cell injury, repair, differentiation and carcinogenesis. In several cell line and animal studies, members of this family, especially ERK2, were critical to transformation and homeostasis of human malignant mesothelioma of the epithelial type [86]. The transcription factor activator protein-1, which is a target of asbestos-induced signalling pathways, was also shown to be critical to the transformation of mesothelial cells through ERK-dependent Fos-related antigen (Fra)-1 elevation [87]. Hepatocyte growth factor (HGF)/scatter factor and its receptor tyrosine kinase, c-Met, are highly expressed in most human malignant mesotheliomas and recently, it was shown that HGF-mediated cell proliferation of human mesothelioma cells through a phosphoinositide 3-kinase (PI3K)/MAP kinase 5/Fra-1 pathway [88]. Moreover, c-Met was shown to be a relevant experimental treatment target as well as a negative prognostic factor [89, 90]. Survival pathways, such as PI3K/Akt/mammalian target of rapamycin (mTOR), are involved in cell growth and resistance to apoptosis, and are often activated in mesothelioma. mTOR was shown to mediate survival signals in many mesothelioma tumours and inhibition of mTOR was also proposed as a nontoxic adjunct to therapy directed against mesothelioma [91]. Inflammation has also been incriminated and it was recently shown that inflammation precedes mesothelioma formation. Moreover, asbestos-induced priming and activation of the NLRP3 (nucleotide-binding domain, leucine repeat containing) inflammasome triggered an autocrine feedback loop modulated via the interleukin (IL)-1 receptor in mesothelial cells, which is targeted in pleural infection, fibrosis and carcinogenesis [92, 93]. A similar mechanism has been shown for carbon nanotubes (CNTs) (see the section on Manmade CNTs).

High-throughput profiling of mRNA by various array platforms has indicated many interesting features of mesothelioma biology, but the results have not been concordant. This may be due to several factors: use of different array platforms with various numbers of genes; and some researchers using cell lines, others correlating human tissue with cell lines and others examining tumour tissue from the parietal pleura of 
lung cancer patients or noncancer patients [50, 94-101]. All these factors may have contributed separately and together to the largely incongruent results.

However, in our genome-wide analysis of six tumour and seven parietal pleura samples, we demonstrated dysregulation of several systems, with overexpression and downregulation of genes reflecting several important biological functions, including DNA replication and repair, and microtubule cytoskeleton organisation and biogenesis [50,71]. Of the DNA repair entity, genes related to double-strand break repair were over-represented. Several key genes encoding proteins known to be targets, but also to confer chemotherapy resistance (e.g. NQO1 (NADPH dehydrogenase, quinone 1), TOP2A (topoisomerase II $\alpha$ ), TYMS (thymidylate synthetase), BIRC5 (survivin) and genes encoding components of the proteasome), and radiotherapy resistance by several DNA repair and damage checkpoint genes (e.g. BRCA2 (breast cancer 2), CHEK1 (checkpoint kinase 1), FANCA (Fanconi anaemia, complementation group A), FANCD2 (Fanconi anaemia, complementation group D2), RAD21 and RAD50), were overexpressed in tumours. A novel angiogenic gene, $A G G F 1$, was also significantly overexpressed. Several genes encoding detoxifying enzymes, among them the multidrug resistance gene ABCB1 (ATP-binding cassette subfamily $\mathrm{B}$ member 1), were downregulated, as were leukocyte transendothelial migration pathway and signal transduction genes.

Despite the low numbers of cases and controls, the differential gene expression detected was highly significant. Genes known to be overexpressed in mesothelioma were overexpressed here (e.g. the Ki67, syndecan 1, survivin and vitronectin). Genes coding for CD15 and sialyl transferase, and negative markers of mesothelioma, such as FUT4 (fucosyltransferase 4) and ST6GALNAC3 ( $\alpha$ - $N$-acetyl-neuraminyl2, 3- $\beta$-galactosyl-1,3)- $N$-acetylgalactosaminide $\alpha$-2,6-sialyltransferase 3), were down-regulated [102]. Unexpectedly, genes encoding calretinin, vascular endothelial growth factor (VEGF) receptor and mesothelin proteins overexpressed in mesothelioma were not differentially expressed. However, recent studies showed that these are also expressed in normal mesothelial cells [103-105].

These studies have resulted in the discovery of a novel biomarker, osteopontin [106], and the proteasome as a novel treatment target [107, 108], as well as a gene signature for prognostication [109], although it has not gained general acceptance yet [110].

Recently, next-generation sequencing of the whole genome uncovered massive genomic damage in mesothelioma versus normal tissue. This was reflected in a significant aneuploidy, and novel, large-scale, inter- and intra-chromosomal deletions, inversions and translocations. Nearly all candidate point mutations appeared to be previously unknown single-nucleotide polymorphisms. One large deletion in DPP10 (dipeptidyl peptidase 10) resulted in altered transcription and expression of DPP10 transcripts correlated with survival in a set of 53 mesotheliomas. Three point mutations were observed in the coding regions of NKX6-2 (a transcription regulator) and NFRKB (a DNA-binding protein involved in modulating NF- $\mathrm{KB}$ ), and amplification of genes such as PCBD2 (pterin- $4 \alpha$-carbinolamine dehydratase/ dimerisation cofactor of hepatocyte nuclear factor $1 \alpha$ ) and DHFR (dihydrofolate reductase), which are involved in growth factor signalling and nucleotide synthesis [111].

\section{Mesothelioma susceptibility and the BAP1 cancer syndrome}

Mesothelioma develops in a minority of asbestos-exposed individuals. This implies some kind of susceptibility to asbestos fibre carcinogenesis. Previous genome-wide association studies (GWASs) on polymorphisms failed to identify a single gene or even a signature of genes that was reproducible [112]. However, some gene polymorphisms showed increased risks of mesothelioma in a subset of studies, including cases not expressing glutathione $S$-transferase $\mu 1$ (GSTM1-null genotype), as well as two variant alleles of the DNA repair genes XRCC1 and XRCC3 [112]. The GSTM1 protein is important for the detoxification of electrophilic compounds, including carcinogens, drugs, environmental toxins and products of oxidative stress, and its downregulation has been associated with several forms of cancer. More recently, the largest GWAS to date on pleural mesothelioma did not reveal any significant new information, other than indicating that genetic risk factors may play a role in the asbestos-associated mesothelioma [113].

Clustering of mesothelioma cases in some families has been observed by several researchers, and some have argued that this is not only due to shared asbestos exposure [114]. A nuclear protein, BAP1, has several proposed functions, including transcriptional regulation, chromatin regulation, and forming part of multiprotein complexes that regulate cellular differentiation, gluconeogenesis, cell cycle checkpoints, transcription and apoptosis [115]. The BAP1 gene is located on chromosome $3 \mathrm{p} 21$, a region that shows loss or deletion in numerous malignant tumours, including $30-60 \%$ of mesotheliomas. In the BAP1 mutation families, there is a dramatically increased incidence of malignant tumours, often developed in an earlier age than observed in the general population [115]. A BAP1 cancer syndrome has been proposed, including mesothelioma, uveal melanoma, cutaneous melanoma and possibly other malignant tumours [116]. Germ-line BAP1 mutations have been described in families with extraordinarily high incidence of 
mesothelioma [116] and in $25 \%$ of sporadic mesotheliomas [117], pointing to BAP1 as the first gene reported to predispose to mesothelioma, but its role in mineral-fibre carcinogenesis has not been established. Furthermore, there are studies showing that BAP1 mutations are significantly more common in epithelial than sarcomatous and biphasic mesotheliomas [118, 119]. The discovery of a susceptibility gene will probably be of major importance for defining high-risk versus low-risk groups when it comes to screening of asbestos-exposed individuals with novel noninvasive biomarkers.

\section{Biomarkers}

\section{Soluble mesothelin-related protein in serum}

Mesothelioma has a long latency period: 20-60 years may elapse between asbestos or other oncogenic exposure and the clinical presentation of disease, and the disease is usually diagnosed in a late stage. Noninvasive diagnostic biomarkers aiding early diagnosis and follow-up of patients have not been available.

The first potential mesothelioma tumour biomarker in serum was soluble mesothelin-related protein (SMRP), also called mesothelin [120], and it emerged as a marker for mesothelioma diagnosis [121]. Mesothelin is a family of proteins that are mainly membrane-bound, and expressed in mesothelial cells as well as various cancers, such as pancreatic and ovarian cancer. The SMRP assay can detect three mesothelin variants, where Variant 1 [120] is the predominant form in serum. SMRP is elevated in patients with epithelial mesothelioma, the most common subtype [122]. Robinson et al. [121] also found SMRP to be elevated 1-5 years before clinical disease in some individuals exposed to asbestos, suggesting that SMRP could be used as a screening test. In addition, elevated SMRP level in serum was recently suggested as an independent negative prognostic factor of mesothelioma [122]. PAss et al. [106] not only found a significant elevation of SMRP in mesothelioma versus lung cancer, but also between stage I and stage II-IV mesothelioma, and, importantly, it was found to be higher in stage I than in noncancer asbestos-exposed individuals. The biological function of mesothelin is largely unknown but it possibly plays a role in cell-cell adhesion. Interestingly, it may also play a role in peritoneal metastasis of ovarian cancer, as cancer antigen (CA)125 expressed on ovarian cancer cell membranes adhere to mesothelin expressed on normal peritoneal cell membranes [123], facilitating local progression along the mesothelium. Mesothelioma cells also co-express CA125 [124], so the typical growth pattern with local progression and even tumour spread from the parietal to the visceral mesothelium could partly be explained by this mechanism.

$\mathrm{SMRP} / \mathrm{mesothelin}$ in serum is a noninvasive marker that can be helpful in making the diagnosis of mesothelioma, as the assay in the pivotal study had a sensitivity of $84 \%$ for mesothelioma, and $100 \%$ specificity in differentiating mesothelioma from other pleural diseases, 95\% against other lung cancers and $100 \%$ against apparently healthy subjects [16]. However, in another study, the best combination of sensitivity and specificity against controls was $66 \%$ and $70.9 \%$, respectively [125]. Moreover, as evaluation of response and recurrence by imaging techniques is difficult in mesothelioma, SMRP level is a sensitive measure of tumour burden as it is increased in more advanced disease [125]. However, this assay failed as an early diagnostic biomarker, as we and others showed no significant difference in preclinical serum levels of cases and controls [126]. Importantly trials are on-going with drugs targeting mesothelin in ovarian cancer, pancreatic cancer and mesothelioma, based on the quite unique expression of mesothelin in these tumours and the lack of expression in vital organs [95]. Thus, mesothelin is currently an important molecule for follow-up of treatment and a putative treatment target for mesothelioma.

\section{3-protein classifier in serum}

Proteomic technology has evolved rapidly and a novel assay based on slow off-rate modified aptamers (SOMAmers) are used as capture reagents in order to achieve highly selective protein detection for biomarker identification [127]. The SOMAmers are short, single-stranded deoxynucleotides with an ability to bind discrete molecular targets. The use of SOMAmers as capture reagents carries many advantages over traditional antibody-based immunoassays, including high sensitivity and specificity, dynamic range, accurate quantification, and reproducibility, and has the ability to measure thousands of human proteins in small volumes of biological samples with low limits of detection. Recently, a 13-protein signature was discovered in a cohort of 117 mesothelioma cases and 142 asbestos-exposed control individuals with a diagnostic area under the curve (AUC) of 0.99 in the training, 0.98 in the independent blinded verification and 0.95 in the blinded validation studies. Sensitivity and specificity were $97 \%$ and $92 \%$ in the training, and $90 \%$ and $95 \%$ in blinded verification, respectively. Sensitivity also correlated with pathological stage: $77 \%$, $93 \%, 96 \%$ and $96 \%$ in stages I-IV, respectively. An alternative decision threshold in the validation study yielding $98 \%$ specificity would still detect $60 \%$ of mesothelioma cases. When compared to mesothelin in a paired sample set, the 13-protein classifier AUC of 0.99 and $91 \% / 94 \%$ sensitivity/specificity were superior to those of mesothelin, with an AUC of 0.82 and a $66 \% / 88 \%$ sensitivity/specificity. The candidate biomarker panel consisted of both inflammatory and proliferative proteins that could be associated with 
asbestos-induced malignancy [128]. However, there have been no prospective studies on asbestos-exposed cohorts to verify their value for early diagnosis and survival.

\section{Fibulin-3 in plasma}

One recently published paper of great interest in the early diagnosis of mesothelioma showed that a previously little-studied protein, fibulin-3, in plasma, could separate asbestos-exposed individuals with mesothelioma from those without mesothelioma, with a sensitivity of $100 \%$ and specificity of $94.1 \%$; blinded validation showed AUC 0.87 for plasma specimens from 96 asbestos-exposed persons as compared with 48 patients with mesothelioma. Moreover, fibulin-3 levels in plasma and pleural effusions were significantly different in patients with effusions from mesothelioma versus other malignant and benign effusions. Tumour tissue was examined for fibulin-3 by immunohistochemical analysis and 26 out of 26 cases were positive [129]. This is, to date, the strongest diagnostic marker for mesothelioma, but it still needs to be validated in thoracic cancer patients without effusions, as well as in prediagnostic samples. This is very important, as the expression of proteins may vary much in early- versus late-stage cancer, and especially in preclinical stages [130].

\section{MicroRNA in plasma}

MicroRNA is a novel class of noncoding RNA with several control functions, and high stability in serum and plasma that was found to discriminate cases from controls in several forms of cancer. Currently, there is evidence that increased circulating plasma concentrations of the microRNA miR-625-3p could serve as a potential diagnostic biomarker for patients with malignant pleural mesothelioma [131].

\section{Manmade CNTs}

Manmade CNTs and disease: the asbestos of the future?

Among nanostructured materials, CNTs are becoming the best known and studied due to their applications as structural materials in electronics, heating elements, batteries, production of stain-resistant fabric, protection of aerospace materials against lighting strikes, water desalinisation and purification, bone grafting, dental implants, targeted drug delivery, and imaging diagnostics [132-134]. The interest in CNTs is a direct consequence of the synthesis of buckminsterfullerene (or fullerene; molecular formula $\mathrm{C}_{60}$ ) and its derivatives in 1985. Fullerene is the third allotropic form of carbon after graphite and diamond [134, 135]. It is a 60-atom carbon molecule in a shape of polyhedral cage made of 12 pentagons and 20 hexagons, and can be considered the paradigm of a family of carbon nanostructures characterised by spherical or tubular shapes. The diameter of a nanotube varies from few nanometres up to several micrometres. The CNTs are of essentially two types, namely, single-walled carbon nanotubes (SWCNTs) and multi-walled carbon nanotubes (MWCNTs) [136, 137]. Although CNTs are widely used in several applications, little is known about their potential toxicity in humans. The main exposure routes in occupational settings are known to be inhalation and dermal contact. Ingestion could also occur as a consequence of swallowing of the inhaled materials following mucociliary clearance or as a result of hand-to-mouth contact [137].

\section{Current evidence for CNT carcinogenesis in the lung and pleura}

Even if the literature on CNT health effects on development of mesothelioma is scarce, several lines of evidence indicate that CNTs behave as biopersistent fibres in vivo and have a carcinogenic potential similar to that of asbestos (fig. 5). By inhalation, a significant fraction of CNTs can remain within the lungs for up to several months [138], and in mice, it was shown that MWCNTs migrate and reach the subpleural tissue after a single inhalation of CNTs [139]. Also in mice, PorTer et al. [140] showed that MWCNTs of about $4 \mu \mathrm{m}$ in length are able to reach the pleura and induce pleural inflammation 56 days after a single aspiration, inducing an "asbestos-like pathogenicity". In a recent publication, rats inhaling sprayed MWCTs weekly for 24 weeks were found to have CNTs that had translocated into the pleural cavity, deposited in the parietal pleura, and induced fibrosis and patchy parietal mesothelial proliferation lesions, very similar to the route and effects of inhaled asbestos [141]. Intraperitoneal injection of MWCTs in heterozygous $\mathrm{p} 53^{+/-}$mice that were followed for 1 year showed a dose-dependent development of mesothelioma, in five out of 20, 17 out of 20, and 19 out of 20 mice by increasing the dose, a proof of the principle that MWCTs can produce mesothelioma and at a very high rate [142]. Moreover, chronic exposure to CNTs showed their invasive potential in human pleural mesothelial cells, through an increased expression of matrix metalloproteinase-2 [144], and recently it was demonstrated that respiratory exposure to MWCNTs in vivo and in vitro induced length-dependent pulmonary fibrosis and epithelial-derived fibroblasts via the transforming growth factor- $\beta / S$ mad pathway [143]. CNTs could also induce metastatic progression of lung carcinoma in mice, mediated by increased local and systemic accumulation of myeloid-derived suppressor cells, as their depletion abrogated pro-tumour activity in vivo [145]. One of the theories on asbestos fibre toxicity and carcinogenicity is the "fibre paradigm" [146], where the geometry of fibres contributes their biopersistence [147]. Similarly, it has been shown that the 
a)

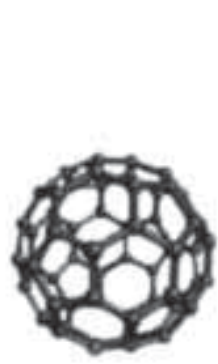

C60

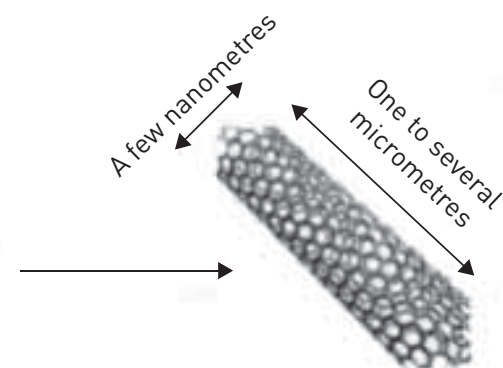

SWCNT

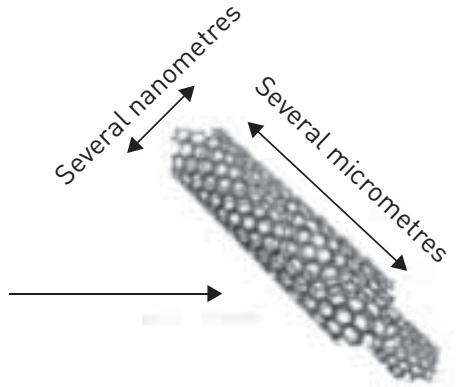

MWCNT

b)

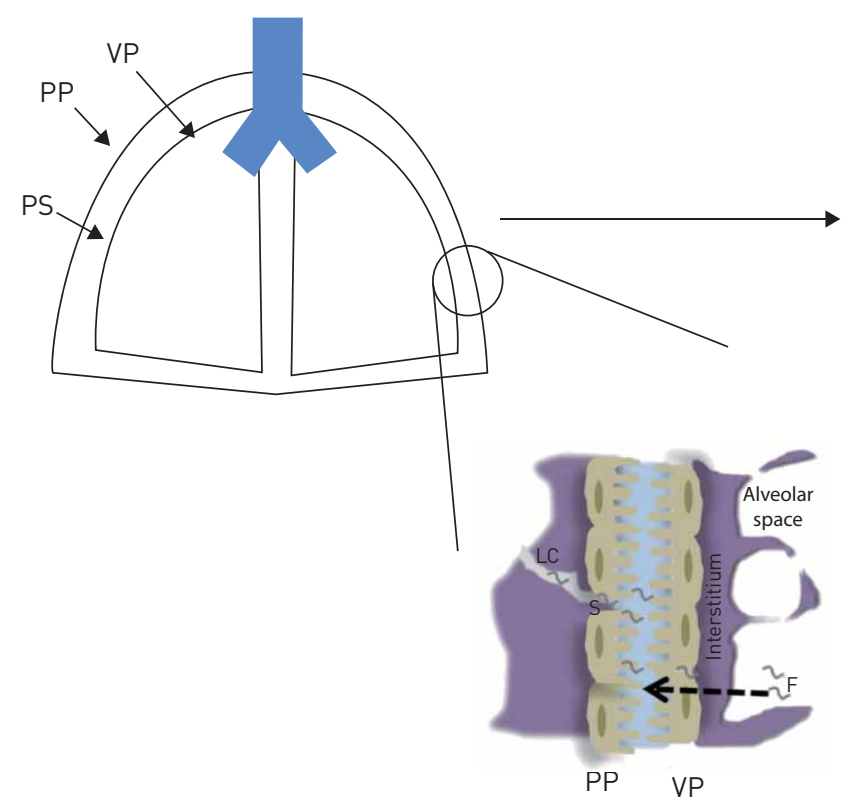

PP damage
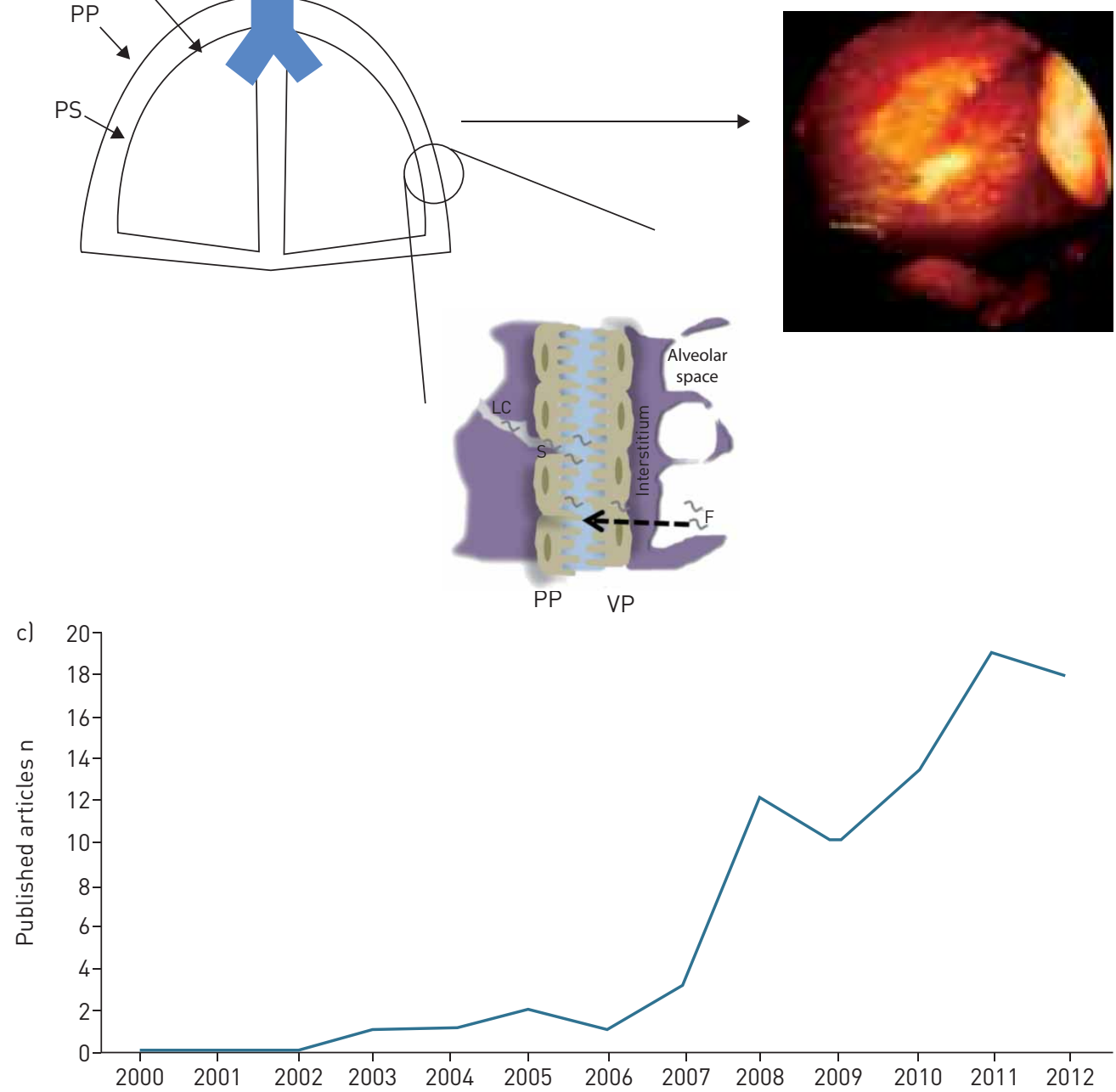

FIGURE 5 Pleural hazard of exposure to carbon nanotubes (CNTs). a) Structures of single-walled CNTs (SWCNTs) and multi-walled CNTs (MWCNTs) derived from buckminsterfullerene $\left(\mathrm{C}_{60}\right)$. The structure of a SWCNT $(<0.4 \mathrm{~nm}$ in diameter) can be conceptualised by wrapping a one-atom-thick layer of graphite (or graphene) into a seamless cylinder. MWCNTs consist of multiple layers of graphite rolled on themselves to form a tube shape with an interlayer spacing of $3.4 \AA$ and a diameter ranging from 1 to $50 \mathrm{~nm}$. b) Schematic sequence of steps leading to pleural damage and/or malignant transformation as a consequence of exposure to biopersistent fibres. Long fibres and CNTs are retained at stomatal openings and induce an inflammatory oxidative stress response, which leads to aberrant reactions at the parietal pleura. Accordingly, the primary lesion caused by biopersistent fibres might form at the parietal pleural; this fact is reflected in pleural mesothelioma staging, where the early mesothelioma is confined to the parietal pleura while more advanced mesothelioma involves the visceral layer. LC: lymph channel; F: fibre; VP: visceral pleura; PP: parietal pleura; PS: pleural space; S: space c) Increasing literature on lung and pleura toxicity induced by CNTs in PubMed, searching for "CNT and pleural toxicity + CNT and mesothelioma". 
CNTs also have a length-dependent toxicity and carcinogenicity [147]. Finally, change of gene expression signatures in the mouse lungs following pharyngeal aspiration MWCNTs were associated with human lung cancer risk and progression signatures [148, 149].

\section{Potential mechanisms of CNT oncogenesis}

As we have reviewed here, several years of studies on asbestos carcinogenicity have not elucidated its oncogenesis fully. Certainly, knowledge of oncogenesis is rudimentary regarding CNTs, but induction of inflammation and gene toxicity seems to be an important component. Interestingly, a significant acute neutrophilic influx into the lungs was demonstrated in animals just 1 day after CNT inhalation, coexisting with histopathological findings coherent with bronchiolitis/alveolitis [150]. The epithelial damage seems to be mediated by reactive oxygen species (ROS), the production of which has been related to the metallic contamination and impurities of CNTs [151, 152]. Moreover, chronic exposure to CNTs affects the immune response, as it determines the sequestration of surfactant proteins A and D (SP-A and SP-D) and collectins, which, in turn, induce macrophage impairments [153]. Indeed, lowered SP-A and SP-D levels reduce resistance to some infections and induce an emphysema-like alteration of the lungs. Moreover, these changes lead to a progressive accumulation of surfactant phospholipid in the lung tissue and alveolar space, and accumulation of apoptotic alveolar macrophages [154]. Although indirect genotoxic CNT action might be related to inflammation and ROS formation, direct CNT DNA damage in cells has been postulated as being responsible for epithelial and mesothelial malignant transformation. Some in vitro and in vivo experiments have shown a direct interaction of MWCNTs with DNA [155], suggesting a genotoxic/mutagenic potential, whereas weaker data are available on SWCNTs $[156,157]$.

Genotoxic damage can occur through direct interaction of retained asbestos fibres and mesothelial cells around the stomata of the parietal pleura as previously described. CNTs have a length-dependent toxicity profile on the mesothelium. Accordingly, long CNTs could be retained around the stomata at the parietal pleura, in a similar fashion to asbestos fibres. It has been reported that macrophages recognise asbestos fibres and CNTs via the class A scavenger receptor MARCO (macrophage receptor with collagenous structure) [158], and that the uptake of both types of fibres activates the NLPR3 inflammasome [159]. Recent data demonstrate that asbestos and erionite induce priming and activation of the NLRP3 inflammasome that modulates, through an autocrine feedback loop, the release of IL-1 $\beta$, IL-6, IL- 8 and VEGF. Production of such critical cytokines and growth factors is probably involved in the initiation of pleural injury and infection, pleural fibrosis, and mesothelioma [160]. Moreover, when exposed to biopersistent fibres, mesothelial cells might avoid apoptosis when stimulated by tumour necrosis factor- $\alpha$ secreted by the activated macrophages. This mechanism has been reported for asbestos and could theoretically be applicable to CNTs [161].

\section{Regulation of health hazards posed by CNTs and future aspects}

In the past decade, CNT-related production capacity has increased at least 10-fold and many companies are investing in diverse applications of CNT, from microelectronics to biotechnology, environmental applications and energy storage [162]. Overall, the production capacity for all CNT products is expected to exceed 12 300 tonnes in 2015 and the total production value is expected to reach US \$1.3 billion in 2015 [163]. With such a multitude of applications, a thorough understanding of the associated toxicity is therefore essential. The evaluation of CNT toxic profiles might take in consideration exposure during manufacturing steps as well as their interaction with biological systems. Preliminary data have demonstrated that the main risk to humans is related to chronic occupational inhalation, mainly during those activities involving high CNT release and uncontrolled exposure. There is an urgent need to test these materials extensively and understand their potential role in causing mesothelioma. In 2013, the US National Institute for Occupational Safety and Health (NIOSH) thoroughly revised their reviews of the animal and other toxicological data relevant to assessing the potential nonmalignant adverse respiratory effects of CNT and proposed a recommended exposure limit (REL) of $1 \mu \mathrm{g} \cdot \mathrm{m}^{-3}$ elemental carbon as a respirable mass (8-h time-weighted average concentration [164]). The NIOSH REL is expected to reduce the risk of pulmonary inflammation and fibrosis. However, given the uncertainty about CNT-associated cancer risk, continued efforts should be made to reduce exposure as much as possible, and a number of strategies for controlling workplace exposures and implementing a medical surveillance programme should be designed. Above all, CNT doses associated with genotoxicity should be determined by in vitro and in vivo studies. To avoid differences in interlaboratory research protocols contributing to conflicting data in the literature, consortium research programmes are emerging to reduce variability and validate findings [165]. In parallel, a number of workplaces should be monitored, from research laboratories to CNT manufacturing, manipulating and recycling plants. Surveillance programmes should be extended worldwide, manufacturers in North America being focused more on SWCNTs, and Asia and Europe (mostly Japan followed by China) leading the production of MWCNTs [166]. Exposure control challenges should involve both the evaluation of exposure control 
techniques, and the management of populations at risk through the identification of work practice recommendations and secondary prevention measures $[167,168]$. Due to the probable latency, follow-up analysis should be performed on CNT-exposed people. It should be noted that preliminary reports suggest that functionalisation allowing CNT solubilisation and enhancing their biocompatibility using water-soluble nanoconjugates seems to be emerging as a safe and effective procedure, with no cytotoxicity on macrophages and epithelial cells $[169,170]$. In conclusion, these observations have the following relevant implications. 1) Although promising in several fields, including pharmaceutics and biomedicine, CNTs could exert a toxic and potentially tumorigenic effect. 2) Based on a similar length-dependent pathogenicity, CNTs may pose an asbestos-like mesothelioma hazard. 3) Nanotoxicology requires a multidisciplinary approach to this kind of problem in order to achieve effective risk control.

\section{Conclusion}

Malignant pleural mesothelioma is a global, manmade cancer problem with increasing death tolls due to sustained mining and use of asbestos. Preventive measures including a global ban on asbestos should be mandatory. Awareness of the potential danger of new manmade fibres with similar carcinogenic properties, exemplified by CNTs, should be high with thorough and relevant testing before their release into society. Novel diagnostic biomarkers are currently being tried for clinical use but we still do not have markers for early diagnosis, prognosis or prediction of therapy. High-throughput molecular profiling of tumours, blood and pleural fluids is currently revealing novel biomarker candidates for earlier diagnosis and novel targets for improved treatment in the future.

\section{Acknowledgements}

We want to thank Chunhui Ni (Nanjing Medical University, Nanjing, China) for valuable and critical review of our manuscript.

\section{References}

1 Dilek Y, Newcomb S, eds. Ophiolite Concept and the Evolution of Geological Thought. Boulder, Geological Society of America, 2003.

2 Engevik A Jr. Bucket-Shaped Pots: Style, Chronology and Regional Diversity in Norway in the Late Roman and Migration Periods. Oxford, Archaeopress, 2008.

Rapp GR. Archaeomineralogy. Berlin, Springer, 2009.

National Toxicology Program. NTP 11th report on carcinogens. Rep Carcinog 2004; 11: A1-A32.

Ribak J, Lilis R, Suzuki Y, et al. Malignant mesothelioma in a cohort of asbestos insulation workers: clinical presentation, diagnosis, and causes of death. Br J Ind Med 2008; 45: 182-187.

6 Wagner JC, Sleggs CA, Marchand P. Diffuse pleural mesothelioma and asbestos exposure in the North Western Cape Province. Br J Ind Med 1960; 17: 260-271.

7 Armstrong BK, Musk AW, Baker JE, et al. Epidemiology of malignant mesothelioma in Western Australia. Med J Aust 1984; 141: 86-88.

8 Gennaro V, Ceppi M, Boffetta P, et al. Pleural mesothelioma and asbestos exposure among Italian oil refinery workers. Scand J Work Environ Health 1994; 20: 213-215.

9 Musk AW, de Klerk NH. Epidemiology of malignant mesothelioma in Australia. Lung Cancer 2004; 45: Suppl. 1, S21-S23.

10 International Agency for Research on Cancer. Asbestos (Chrysolite, Amosite, Crocidolite, Tremolite, Actinolite, and Anthophyllite). In: IARC Monographs. Arsenic, Metals, Fibres and Dusts. Lyon, International Agency for Research on Cancer, 2009; pp. 147-167.

11 Morinaga K, Kishimoto T, Sakatani M, et al. Asbestos-related lung cancer and mesothelioma in Japan. Ind Health 2001; 39: 65-74

12 Barrett JC, Lamb PW, Wiseman RW. Multiple mechanisms for the carcinogenic effects of asbestos and other mineral fibers. Environ Health Perspect 1989; 81: 81-89.

13 Stanton MF, Wrench C. Mechanisms of mesothelioma induction with asbestos and fibrous glass. J Natl Cancer Inst 1972; 48: 797-821.

14 Lippmann M. Deposition and retention of inhaled fibres: effects on incidence of lung cancer and mesothelioma. Occup Environ Med 1994; 51: 793-798.

15 Wagner JC, Berry G, Skidmore JW, et al. The effects of the inhalation of asbestos in rats. Br J Cancer 1974; 29: 252-269.

16 Robinson BW, Musk AW, Lake RA. Malignant mesothelioma. Lancet 2005; 366: 397-408.

17 European Union. Commission Directive 1999/77/EC of 26 July 1999. Off J Eur Comm 1999; L207: 18-20.

18 Bernstein DM, Rogers RA, Sepulveda R, et al. The pathological response and fate in the lung and pleura of chrysotile in combination with fine particles compared to amosite asbestos following short-term inhalation exposure: interim results. Inhal Toxicol 2010; 22: 937-962.

19 Ferrante D, Bertolotti M, Todisco A, et al. Cancer mortality and incidence of mesothelioma in a cohort of wives of asbestos workers in Casale Monferrato, Italy. Environ Health Perspect 2007; 115: 1401-1405.

20 Peto J, Decarli A, La Vecchia C, et al. The European mesothelioma epidemic. Br J Cancer 1999; 79: 666-672.

21 Tossavainen A. Global use of asbestos and the incidence of mesothelioma. Int J Occup Environ Health 2004; 10: $22-22$.

22 World Health Organization. Elimination of Asbestos-Related Diseases. Geneva, WHO, 2006.

23 Bianchi C, Bianchi T. Malignant mesothelioma: global incidence and relationship with asbestos. Ind Health 2007; 45: 379-387.

24 Gaafar RM, Eldin NH. Epidemic of mesothelioma in Egypt. Lung Cancer 2005; 49: Suppl. 1, S17-S20. 
Takahashi K, Karjalainen A. A cross-country comparative overview of the asbestos situation in ten Asian countries. Int J Occup Environ Health 2003; 9: 244-248.

Luo S, Liu X, Mu S, et al. Asbestos related diseases from environmental exposure to crocidolite in Da-yao, China. I. Review of exposure and epidemiological data. Occup Environ Med 2003; 60: 35-41.

Joshi TK, Bhuva UB, Katoch P. Asbestos ban in India: challenges ahead. Ann NY Acad Sci 2006; 1076: $292-308$. Baris YI, Sahin AA, Ozesmi M, et al. An outbreak of pleural mesothelioma and chronic fibrosing pleurisy in the village of Karain/Urgup in Anatolia. Thorax 1978; 33: 181-119.

Virta RL. US Geological Survey: Mineral Commodity Summaries - Asbestos. http://minerals.usgs.gov/minerals/ pubs/commodity/asbestos/mcs-2013-asbes.pdf Date last updated: January 2013.

Sakellariou K, Malamou-Mitsi V, Haritou A, et al. Malignant pleural mesothelioma from nonoccupational asbestos exposure in Metsovo (north-west Greece): slow end of an epidemic? Eur Respir J 1996; 9: 1206-1210.

Roushdy-Hammady I, Siegel J, Emri S, et al. Genetic-susceptibility factor and malignant mesothelioma in the Cappadocian region of Turkey. Lancet 2001; 357: 444-445.

Metintas S, Metintas M, Ucgun I, et al. Malignant mesothelioma due to environmental exposure to asbestos: follow-up of a Turkish cohort living in a rural area. Chest 2002; 122: 2224-2229.

Yoshikawa Y, Sato A, Tsujimura T, et al. Frequent inactivation of the BAP1 gene in epithelioid-type malignant mesothelioma. Cancer Sci 2012; 103: 868-874.

Travis LB, Fossa SD, Schonfeld SJ, et al. Second cancers among 40,576 testicular cancer patients: focus on long-term survivors. J Natl Cancer Inst 2005; 97: 1354-1365.

Goodman JE, Nascarella MA, Valberg PA. Ionizing radiation: a risk factor for mesothelioma. Cancer Causes Control 2009; 20: 1237-1254.

Hodgson DC, Gilbert ES, Dores GM, et al. Long-term solid cancer risk among 5-year survivors of Hodgkin's lymphoma. J Clin Oncol 2007; 25: 1489-1497.

Carbone M, Pass HI, Rizzo P, et al. Simian virus 40-like DNA sequences in human pleural mesothelioma. Oncogene 1994; 9: 1781-1790.

Hilleman MR. Discovery of simian virus 40 (SV40) and its relationship to poliomyelitis virus vaccines. Dev Biol Stand 1998; 94: 183-190.

Carbone M, Stach R, Di Resta I, et al. Simian virus 40 oncogenesis in hamsters. Dev Biol Stand 1998; 94: $273-279$. Poulin DL, DeCaprio JA. Is there a role for SV40 in human cancer? J Clin Oncol 2006; 24: 4356-4365. Bergsagel DJ, Finegold MJ, Butel JS, et al. DNA sequences similar to those of simian virus 40 in ependymomas and choroid plexus tumors of childhood. N Engl J Med 1992; 326: 988-993.

Vilchez RA, Madden CR, Kozinetz CA, et al. Association between simian virus 40 and non-Hodgkin lymphoma. Lancet 2002; 359: 817-823.

Vilchez RA, Kozinetz CA, Arrington AS, et al. Simian virus 40 in human cancers. Am J Med 2003; 114: 675-684. Strickler HD. A multicenter evaluation of assays for detection of SV40 DNA and results in masked mesothelioma specimens. Cancer Epidemiol Biomarkers Prev 2001; 10: 523-532.

Manfredi JJ, Dong J, Liu WJ, et al. Evidence against a role for SV40 in human mesothelioma. Cancer Res 2005; 65: 2602-2609.

Stratton K, Almario DA, McCormik MC, eds. Institute of Medicine (US). Immunization Safety Review: SV40 Contamination of Polio Vaccine and Cancer. Washington, National Academies Press, 2002.

Robinson C, van Bruggen I, Segal A, et al. A novel SV40 TAg transgenic model of asbestos-induced mesothelioma: malignant transformation is dose dependent. Cancer Res 2006; 66: 10786-10794.

Kroczynska B, Cutrone R, Bocchetta M, et al. Crocidolite asbestos and SV40 are cocarcinogens in human mesothelial cells and in causing mesothelioma in hamsters. Proc Natl Acad Sci USA 2006; 103: 14128-14133.

Cristaudo A, Foddis R, Vivaldi A, et al. SV40 enhances the risk of malignant mesothelioma among people exposed to asbestos: a molecular epidemiologic case-control study. Cancer Res 2005; 65: 3049-3052.

Røe OD, Anderssen E, Helge E, et al. Genome-wide profile of pleural mesothelioma versus parietal and visceral pleura: the emerging gene portrait of the mesothelioma phenotype. PLoS One 2009; 4: e6554.

Hinescu ME, Gherghiceanu M, Suciu L, et al. Telocytes in pleura: two- and three-dimensional imaging by transmission electron microscopy. Cell Tissue Res 2011; 343: 389-397.

Mutsaers SE. The mesothelial cell. Int J Biochem Cell Biol 2004; 36: 9-16.

Light RW, Lee YCG, eds. Textbook of Pleural Diseases. 1st Edn. London, Arnold, 2003.

Taskinen E, Ahlamn K, Wukeri M. A current hypothesis of the lymphatic transport of inspired dust to the parietal pleura. Chest 1973; 64: 193-196.

Sebastien P, Janson X, Gaudichet A, et al. Asbestos retention in human respiratory tissues: comparative measurements in lung parenchyma and in parietal pleura. IARC Sci Publ 1980; 30: 237-246.

Boulanger G, Andujar P, Pairon JC, et al. Quantification of short and long asbestos fibers to assess asbestos exposure: a review of fiber size toxicity. Environ Health 2014; 13: 59.

McDonald JC, Armstrong BG, Edwards CW, et al. Case-referent survey of young adults with mesothelioma: I. Lung fibre analyses. Ann Occup Hyg 2001; 45: 513-518.

Bridda A, Padoan I, Mencarelli R, et al. Peritoneal mesothelioma: a review. MedGenMed 2007; 9: 32.

Herrick SE, Mutsaers SE. Mesothelial progenitor cells and their potential in tissue engineering. Int J Biochem Cell Biol 2004; 36: 621-642.

Bolen JW, Hammar SP, McNutt MA. Reactive and neoplastic serosal tissue. A light-microscopic, ultrastructural, and immunocytochemical study. Am J Surg Pathol 1986; 10: 34-47.

Kettunen E, Nissen AM, Ollikainen T, et al. Gene expression profiling of malignant mesothelioma cell lines: cDNA array study. Int J Cancer 2001; 91: 492-496.

Kim JC, Badano JL, Sibold S, et al. The Bardet-Biedl protein BBS4 targets cargo to the pericentriolar region and is required for microtubule anchoring and cell cycle progression. Nat Genet 2004; 36: 462-470.

Kothmaier H, Quehenberger F, Halbwedl I, et al. EGFR and PDGFR differentially promote growth in malignant epithelioid mesothelioma of short and long term survivors. Thorax 2008; 63: 345-351.

Rinkevich Y, Mori T, Sahoo D, et al. Identification and prospective isolation of a mesothelial precursor lineage giving rise to smooth muscle cells and fibroblasts for mammalian internal organs, and their vasculature. Nat Cell Biol 2012; 14: 1251-1260. 
Boutin C, Schlesser M, Frenay C, et al. Malignant pleural mesothelioma. Eur Respir J 1998; 12: 972-981. Acevedo-Duncan M, Patel R, Whelan S, et al. Human glioma PKC-1 and PKC-BII phosphorylate cyclindependent kinase activating kinase during the cell cycle. Cell Prolif 2002; 35: 23-36. Jaurand MC, Fleury-Feith J. Pathogenesis of malignant pleural mesothelioma. Respirology 2005; 10: 2-8.

Jean D, Daubriac J, Le Pimpec-Barthes F, et al. Molecular changes in mesothelioma with an impact on prognosis and treatment. Arch Pathol Lab Med 2012; 136: 277-293.

Fennell DA. Genetics and molecular biology of mesothelioma. Recent Results Cancer Res 2011; 189: 149-167. normal pleura and predict lung asbestos burden and clinical outcome. Cancer Res 2009; 69: 227-234.

Roe OD, Anderssen E, Sandeck H, et al. Malignant pleural mesothelioma: genome-wide expression patterns reflecting general resistance mechanisms and a proposal of novel targets. Lung Cancer 2010; 67: 57-68.

Gee GV, Koestler DC, Christensen BC, et al. Downregulated microRNAs in the differential diagnosis of malignant pleural mesothelioma. Int J Cancer 2010; 127: 2859-2869.

Hosako M, Muto T, Nakamura $\mathrm{Y}$, et al. Proteomic study of malignant pleural mesothelioma by laser microdissection and two-dimensional difference gel electrophoresis identified cathepsin D as a novel candidate for a differential diagnosis biomarker. J Proteomics 2012; 75: 833-844

Jaurand MC, Kheuang L, Magne L, et al. Chromosomal changes induced by chrysotile fibres or benzo-3,4-pyrene in rat pleural mesothelial cells. Mutat Res 1986; 169: 141-148.

Bignon J, Jaurand MC. Biological in vitro and in vivo responses of chrysotile versus amphiboles. Environ Health Perspect 1983; 51: 73-80.

Suzuki Y, Yuen SR, Ashley R. Short, thin asbestos fibers contribute to the development of human malignant mesothelioma: pathological evidence. Int J Hyg Environ Health 2005; 208: 201-210.

Ashburner M, Ball CA, Blake JA, et al. Gene ontology: tool for the unification of biology. The Gene Ontology Consortium. Nat Genet 2000; 25: 25-29.

Murthy SS, Testa JR. Asbestos, chromosomal deletions, and tumor suppressor gene alterations in human malignant mesothelioma. J Cell Physiol 1999; 180: 150-157.

Assoian RK, Yung Y. A reciprocal relationship between Rb and Skp2: implications for restriction point control, signal transduction to the cell cycle and cancer. Cell Cycle 2008; 7: 24-27.

Yang CT, You L, Yeh CC, et al. Adenovirus-mediated p14 ${ }^{\mathrm{ARF}}$ gene transfer in human mesothelioma cells. J Natl Cancer Inst 2000; 92: 636-641.

Giacinti C, Giordano A. RB and cell cycle progression. Oncogene 2006; 25: 5220-5227. pathway, a possible mechanism for asbestos-induced oncogenesis. Proc Natl Acad Sci USA 2006; 103: $10397-10402$.

Sartore-Bianchi A, Gasparri F, Galvani A, et al. Bortezomib inhibits nuclear factor- $\mathrm{kB}$ dependent survival and has potent in vivo activity in mesothelioma. Clin Cancer Res 2007; 13: 5942-5951.

Altieri DC. The case for survivin as a regulator of microtubule dynamics and cell-death decisions. Curr Opin Cell Biol 2006; 18: 609-615.

Dora K, Nurminen M, Hjerpe A. Growth factors regulate the expression profile of their syndecan co-receptors and the differentiation of mesothelioma cells. Anticancer Res 2003; 23: 2435-2444.

Shukla A, Hillegass JM, MacPherson MB, et al. ERK2 is essential for the growth of human epithelioid malignant mesotheliomas. Int J Cancer 2011; 129: 1075-1086.

Ramos-Nino ME, Timblin CR, Mossman BT. Mesothelial cell transformation requires increased AP-1 binding activity and ERK-dependent Fra-1 expression. Cancer Res 2002; 62: 6065-6069.

Ramos-Nino ME, Blumen SR, Sabo-Attwood T, et al. HGF mediates cell proliferation of human mesothelioma cells through a PI3K/MEK5/Fra-1 pathway. Am J Respir Cell Mol Biol 2008; 38: 209-217.

Jagadeeswaran R, Ma PC, Seiwert TY, et al. Functional analysis of c-Met/hepatocyte growth factor pathway in malignant pleural mesothelioma. Cancer Res 2006; 66: 352-361.

Levallet G, Vaisse-Lesteven M, Le Stang N, et al. Plasma cell membrane localization of c-MET predicts longer survival in patients with malignant mesothelioma: a series of 157 cases from the MESOPATH Group. $J$ Thorac Oncol 2012; 7: 599-606.

Wilson SM, Barbone D, Yang TM, et al. mTOR mediates survival signals in malignant mesothelioma grown as tumor fragment spheroids. Am J Respir Cell Mol Biol 2012; 39: 576-583.

Hillegass JM, Miller JM, MacPherson MB, et al. Asbestos and erionite prime and activate the NLRP3 inflammasome that stimulates autocrine cytokine release in human mesothelial cells. Part Fibre Toxicol 2013; 10: 39.

Hillegass JM, Shukla A, Lathrop SA, et al. Inflammation precedes the development of human malignant mesotheliomas in a SCID mouse xenograft model. Ann NY Acad Sci 2010; 1203: 7-14.

Hashimoto K, Araki K, Osaki M, et al. MCM2 and Ki-67 expression in human lung adenocarcinoma: prognostic implications. Pathobiology 2004; 71: 193-200.

Hassan R, Ho M. Mesothelin targeted cancer immunotherapy. Eur J Cancer 2008; 44: 46-53. malignant mesothelioma. Chest 2004; 125: 1843-1852.

Jacquemont C, Taniguchi T. Proteasome function is required for DNA damage response and fanconi anemia pathway activation. Cancer Res 2007; 67: 7395-7405.

Jackson DE. The unfolding tale of PECAM-1. FEBS Lett 2003; 540: 7-14. degradation. Proc Natl Acad Sci USA 2005; 102: 1649-1654.

Jung BH, Beck SE, Cabral J, et al. Activin type 2 receptor restoration in MSI-H colon cancer suppresses growth and enhances migration with activin. Gastroenterology 2007; 132: 633-644.

Kanehisa M, Araki M, Goto S, et al. KEGG for linking genomes to life and the environment. Nucleic Acids Res 2008; 36: D480-D484.

Kauffmann A, Rosselli F, Lazar V, et al. High expression of DNA repair pathways is associated with metastasis in melanoma patients. Oncogene 2008; 27: 565-573. 

malignant pleural mesotheliomas revealed by combined use of cDNA and tissue microarray. Carcinogenesis 2005; 26: $17-25$.

104 Kennedy RD, D'Andrea AD. DNA repair pathways in clinical practice: lessons from pediatric cancer susceptibility syndromes. J Clin Oncol 2006; 24: 3799-3808.

105 Thickett DR, Armstrong L, Millar AB. Vascular endothelial growth factor (VEGF) in inflammatory and malignant pleural effusions. Thorax 1999; 54: 707-710.

106 Pass HI, Lott D, Lonardo F, et al. Asbestos exposure, pleural mesothelioma, and serum osteopontin levels. N Engl $J$ Med 2008; 53: 1564-1573.

107 Sun X, Gulyas M, Hjerpe A, et al. Proteasome inhibitor PSI induces apoptosis in human mesothelioma cells. Cancer Lett 2006; 232: 161-169.

108 the ubiquitin-proteasome pathway as . Gordon GJ, Rockwell GN, Godfrey PA, et al. Validation of genomics-based prognostic tests in malignant pleural mesothelioma. Clin Cancer Res 2005; 11: 4406-4414.

110 Lopez-Rios F, Chuai S, Flores R, et al. Global gene expression profiling of pleural mesotheliomas: overexpression of aurora kinases and P16/CDKN2A deletion as prognostic factors and critical evaluation of microarray-based prognostic prediction. Cancer Res 2006; 66: 2970-2979.

111 Bueno R, De Rienzo A, Dong L, et al. Second generation sequencing of the mesothelioma tumor genome. PLoS One 2010; 5: e10612.

112 Neri M, Ugolini D, Dianzani I, et al. Genetic susceptibility to malignant pleural mesothelioma and other asbestos-associated diseases. Mutat Res 2008; 659: 126-136.

113 Matullo G, Guarrera S, Betti M, et al. Genetic variants associated with increased risk of malignant pleural mesothelioma: a genome-wide association study. PLoS One 2013; 8: e61253.

114 Ugolini D, Neri M, Ceppi M, et al. Genetic susceptibility to malignant mesothelioma and exposure to asbestos: the influence of the familial factor. Mutat Res 2013; 658: 162-171.

115 Carbone M, Yang H, Pass HI, et al. BAP1 and cancer. Nat Rev Cancer 2013; 13: 153-159.

116 Testa JR, Cheung M, Pei J, et al. Germline BAP1 mutations predispose to malignant mesothelioma. Nat Genet 2011; 43: 1022-1025.

117 Carbone M, Yang H. Molecular pathways: targeting mechanisms of asbestos and erionite carcinogenesis in mesothelioma. Clin Cancer Res 2012; 18: 598-604. Bott M, Brevet M, Taylor BS, et al. The nuclear deubiquitinase BAP1 is commonly inactivated by somatic mutations and 3p21.1 losses in malignant pleural mesothelioma. Nat Genet 2011; 43: 668-672. Yoshikawa Y, Sato A, Tsujimura T, et al. Frequent inactivation of the BAP1 gene in epithelioid-type malignant mesothelioma. Cancer Sci 2012; 103: 868-874.

Beyer HL, Geschwindt RD, Glover CL, et al. MESOMARK: a potential test for malignant pleural mesothelioma. Clin Chem 2007; 53: 666-672.

121 Robinson BW, Creaney J, Lake R, et al. Mesothelin-family proteins and diagnosis of mesothelioma. Lancet 2003; 362: 1612-1616.

122 Grigoriu BD, Scherpereel A, Devos P, et al. Utility of osteopontin and serum mesothelin in malignant pleural mesothelioma diagnosis and prognosis assessment. Clin Cancer Res 2007; 13: 2928-2935.

123 Gubbels JA, Belisle J, Onda M, et al. Mesothelin-MUC16 binding is a high affinity, N-glycan dependent interaction that facilitates peritoneal metastasis of ovarian tumors. Mol Cancer 2006; 5: 50.

124 Rump A, Morikawa Y, Tanaka M, et al. Binding of ovarian cancer antigen CA125/MUC16 to mesothelin mediates cell adhesion. J Biol Chem 2004; 279: 9190-9198.

125 Azim HA Jr., Gaafar R, Abdel Salam I, et al. Soluble mesothelin-related protein in malignant pleural mesothelioma. J Egypt Natl Canc Inst 2008; 20: 224-229.

126 Roe OD, Creaney J, Lundgren S, et al. Mesothelin-related predictive and prognostic factors in malignant mesothelioma: a nested case-control study. Lung Cancer 2008; 61: 235-243.

127 Kraemer S, Vaught JD, Bock C, et al. From SOMAmer-based biomarker discovery to diagnostic and clinical applications: a SOMAmer-based, streamlined multiplex proteomic assay. PLoS One 2011; 6: e26332. Ostroff RM, Mehan MR, Stewart A, et al. Early detection of malignant pleural mesothelioma in asbestos-exposed individuals with a noninvasive proteomics-based surveillance tool. PLoS One 2012; 7: e46091. Pass HI, Levin SM, Harbut MR, et al. Fibulin-3 as a blood and effusion biomarker for pleural mesothelioma. N Engl J Med 2012; 367: 1417-1427.

130 Kirschner MB, Cheng YY, Badrian B, et al. Increased circulating miR-625-3p: a potential biomarker for patients with malignant pleural mesothelioma. J Thorac Oncol 2012; 7: 1184-1191.

131 Creaney J, Dick IM, Meniawy TM, et al. Comparison of fibulin-3 and mesothelin as markers in malignant mesothelioma. Thorax 2014; 69: 895-902.

132 Buzea C, Pacheco II, Robbie K. Nanomaterials and nanoparticles: sources and toxicity. Biointerphases 2007; 2: MR17-MR71.

133 Lu F, Gu L, Meziani MJ, et al. Advances in bioapplications of carbon nanotubes. Adv Mater 2009; 21: 139-152.

134 Prato M, Kostarelos K, Bianco A. Functionalized carbon nanotubes in drug design and discovery. Acc Chem Res 2008; 41: 60-68.

Krätschmer K, Lamb L, Fostiropoulos K, et al. Solid $\mathrm{C}_{60}$ : a new form of carbon. Nature 1990; 347; 354-335. Iijima S, Ichihashi T. Single-shell carbon nanotubes of $1 \mathrm{~nm}$ diameter. Nature 1993; 363: 603-605.

Kwon YK, Tomanek D. Electronic and structural properties of multiwall carbon nanotubes. Physical Rev B 1998; 58: R16001-R16004.

Elgrabli D, Floriani M, Abella-Gallart S, et al. Biodistribution and clearance of instilled carbon nanotubes in rat lung. Part Fibre Toxicol 2008; 5: 20.

Ryman-Rasmussen JP, Cesta MF, Brody AR, et al. Inhaled carbon nanotubes reach the subpleura tissue in mice. Nat Nanotech 2009; 4: 747-751.

Porter DW, Hubbs AF, Mercer RR, et al. Mouse pulmonary dose- and time course-responses induced by exposure to multi-walled carbon nanotubes. Toxicology 2010; 269: 136-147. 
$141 \mathrm{Xu} \mathrm{J}$, Alexander DB, Futakuchi $\mathrm{M}$, et al. Size- and shape-dependent pleural translocation, deposition, fibrogenesis, and mesothelial proliferation by multiwalled carbon nanotubes. Cancer Sci 2014; 105: 763-769.

142 Takagi A, Hirose A, Futakuchi $\mathrm{M}$, et al. Dose-dependent mesothelioma induction by intraperitoneal administration of multi-wall carbon nanotubes in p53 heterozygous mice. Cancer Sci 2012; 103: 1440-1444.

143 Lohcharoenkal W, Wang L, Stueckle TA, et al. Chronic exposure to carbon nanotubes induces invasion of human mesothelial cells through matrix metalloproteinase-2. ACS Nano 2013; 7: 7711-7723.

144 Chen T, Nie H, Gao X, et al. Epithelial-mesenchymal transition involved in pulmonary fibrosis induced by multi-walled carbon nanotubes via TGF-beta/Smad signaling pathway. Toxicol Lett 2014; 226: 150-162.

145 Shvedova AA, Tkach AV, Kisin ER, et al. Carbon nanotubes enhance metastatic growth of lung carcinoma via up-regulation of myeloid-derived suppressor cells. Small 2013; 9: 1691-1695.

146 Varga C, Szendi K. Carbon nanotubes induce granulomas but not mesotheliomas. In Vivo 2010; 24: 82.

147 Donaldson K, Murphy F, Shinwald A, et al. Identifying the pulmonary hazard of high aspect ratio nanoparticles to enable their safety-by-design. Nanomedicine 2011; 6: 143-115.

148 Guo NL, Wan YW, Denvir J, et al. Multiwalled carbon nanotube-induced gene signatures in the mouse lung: potential predictive value for human lung cancer risk and prognosis. J Toxicol Environ Health A 2012; 75: 1129-1153.

149 Pacurari M, Qian Y, Porter DW, et al. Multi-walled carbon nanotube-induced gene expression in the mouse lung: association with lung pathology. Toxicol Appl Pharmacol 2011; 255: 18-31.

150 Bonner JC, Silva RM, Taylor AJ, et al. Interlaboratory evaluation of rodent pulmonary responses to engineered nanomaterials: the NIEHS Nano GO Consortium. Environ Health Perspect 2013; 121: 676-678.

151 Pacurari M. Raw single-wall carbon nanotubes induce oxidative stress and activate MAPKs, AP-1, NKkB and Akt in normal and malignant human mesothelial cells. Environ Health Perspect 2008; 116: 121

152 Stella GM. Carbon nanotubes and pleural damage: perspectives of nanosafety in the light of asbestos experience. Biointerphases 2011; 6: P1-P17.

153 Salvador-Morales C, Townsend P, Flahaut E, et al. Binding of pulmonary surfactant proteins to carbon nanotubes; potential for damage to lung immune defense mechanisms. Carbon 2007; 45: 607-617.

154 Botas C, Poulain F, Akiyama J, et al. Altered surfactant homeostasis and alveolar type II cell morphology in mice lacking Surfactant protein D. Proc Natl Acad Sci USA 1998; 95: 11869-11874.

155 Kato T, Totsuka Y, Ishino K, et al. Genotoxicity of multi-walled carbon nanotubes in both in vitro and in vivo assay systems. Nanotoxicology 2013; 7: 452-461

156 Lindberg HK, Falck GC, Suhonen S, et al. Genotoxicity of nanomaterials: DNA damage and micronuclei induced by carbon nanotubes and graphite nanofibers in human bronchial epithelial cells in vitro. Toxicol Lett 2009; 186: $166-173$.

157 Kim JS, Song KS, Yu IJ. Evaluation of in vitro and in vivo genotoxicity of single-walled carbon nanotubes. Toxicol Ind Health 2013 [In press DOI: 10.1177/0748233713483201].

158 Hirano S, Kanno S, Furuyama A. Macrophage receptor with collagenous structure (MARCO) is a dynamic adhesive molecule that enhances uptake of carbon nanotubes by CHO-KI cells. Toxicol Appl Pharmacol 2011; 259: 96-103.

159 Palomaki J, Valimaki E, Sund J. Long, needle-like carbon nanotubes and asbestos activate the NLPR3 inflammasome sensing of asbestos and silica. ACS Nano 2011; 5: 6861-6870.

160 Hillegass JM, Miller JM, Macpherson MB, et al. Asbestos and erionite prime and activate the NLRP3 inflammasome that stimulates autocrine cytokine release in human mesothelial cells. Part Fibre Toxicol 2013; 10: 3.

161 Bhattacharya K, Andón FT, El-Sayed R, et al. Mechanisms of carbon nanotube-induced toxicity: Focus on pulmonary inflammation. Adv Drug Deliv Rev 2013; 65: 2087-2097.

162 De Violder MFL, Tawfick SH, Baughman RH, et al. Carbon nanotubes: present and future commercial applications. Science 2013; 339: 535-539.

163 Parish A. Production and application of carbon nanotubes, carbon nanofibres, fullerenes, graphene and nondiamonds: a global technology survey and marketing analysis. Stamford, Innovative Research and Products Inc., 2011.

164 National Institute for Occupational Safety and Health. Carbon nanotubes and nanofibers: NIOSH seeks comment on draft recommendations, research needs. www.cdc.gov/niosh/updates/upd-12-02-10.html Date last updated: December 2, 2010.

165 Xia T, Hamilton RF, Bonner JC, et al. Interlaborator evaluation of in vitro cytotoxicity and inflammatory responses to engineered nanomaterials: the NIEHS Nano GO Consortium. Environ Health Perspect 2013; 121: 683-690.

166 Thiele C, Das R. Carbon Nanotubes and Graphene for Electronics Applications: Technologies, Players \& Opportunities. Cambridge, IDTechEX, 2009.

167 Castranova V, Schulte PA, Zumwalde RD. Occupational nanosafety considerations for carbon nanotubes and carbon nanofibers. Acc Chem Res 2013; 46: 642-649.

168 Shulte PA, Kuemperl ED, Zumwalde RD, et al. Focused actions to protect carbon nanotube workers. Am J Ind Med 2012; 55: 395-411.

169 Dvash R, Khatchatouriants A, Solmesky LJ, et al. Structural and biological performance of phospholipidhyaluronan functionalized single-walled carbon nanotubes. J Control Dis 2013; 170: 295-305.

170 Mehara NK, Jain NK. Development, characterization and cancer targeting potential of surface engineered carbon nanotubes. J Drug Target 2013; 8: 745-758. 